\title{
The wrong and wounding road: Paediatric polytrauma admitted to a level 1 trauma intensive care unit over a 5-year period
}

\author{
N Naidoo, MB ChB; D J J Muckart, FRCS, MMSc Crit Care (SA) \\ Department of Surgery, School of Clinical Medicine, College of Health Sciences, Nelson R Mandela School of Medicine, \\ University of KwaZulu-Natal, Durban, South Africa
}

Corresponding author: DJ J Muckart (davidmuc@ialch.co.za)

\begin{abstract}
Background. Injury in childhood is a major cause of potentially preventable morbidity and mortality. In order to implement effective preventive strategies, epidemiological data on mechanisms of injury and outcome are essential.

Objectives. To assess the causation, severity of injury, morbidity and mortality of paediatric trauma admitted to a level 1 trauma intensive care unit (TICU).

Methods. Children were defined as being $<16$ years of age. The study covered the 5-year period January 2008 - December 2012. Eligible patients were identified from a prospective database maintained in the level 1 TICU at Inkosi Albert Luthuli Central Hospital, Durban, South Africa. Data extracted were referral source, mechanism of injury, age and gender distribution, injury severity score (ISS), anatomical distribution of injury and mortality.

Results. A total of 181 patients admitted during the study period accounted for $15.9 \%$ of all admissions. There were 84 females (46.4\%) and 97 males (53.6\%), with a median age of 7 years (interquartile range (IQR) 4 - 10). Sources of admission were directly from the scene in 38 cases $(21.0 \%)$, from a primary healthcare facility in $47(26.0 \%)$, from a regional hospital in $56(31.0 \%)$ and from a tertiary facility in $40(22.0 \%)$. Mortality rates according to location of transfer were regional hospital 8 deaths $(30.8 \%)$, tertiary facility 7 (26.9\%), primary health clinic 7 (26.9\%), and from the scene 4 (15.4\%). Mechanisms of injury were pedestrian-motor vehicle collision (PMVC) in 105 cases (58.0\%), motor vehicle passenger in $38(21.0 \%)$, non-vehicular blunt trauma in 18 (10.0\%), gunshot wounds (GSWs) in 12 (6.6\%), stab wounds in $6(3.3 \%)$, bull goring in $1(0.5 \%)$ and bicycle accident $1(0.5 \%)$. The median ISS for all admissions was 25 (IQR $16-38$ ). ISSs were $>25$ in 98 patients (54.1\%), 16 - 25 in 51 (28.2\%), 9 - 15 in 9 (4.9\%) and $<9$ in 13 (7.2\%); 61.9\% of patients had head injuries, $48.1 \%$ injuries to the extremities, $41.4 \%$ abdominal trauma, $40.3 \%$ thoracic trauma, $20.4 \%$ external soft-tissue trauma, $9.9 \%$ cervical injury and 9.4\% facial trauma. There were 26 deaths (14.4\%), of which PMVCs accounted for 16 (61.5\%), motor vehicle passengers for 7 (26.9\%), blunt trauma for $2(7.7 \%)$ and GSWs for $1(3.8 \%)$. The majority of deaths $(92 \%)$ were of patients with an ISS $>25$. Of the 26 patients who died, $88.4 \%$ had a head injury, $46.2 \%$ an extremity injury, $38.5 \%$ an external injury, $34.6 \%$ abdominal or chest injuries, $19.2 \%$ neck injury and $11.5 \%$ facial injury.

Conclusions. Motor vehicle-related injuries, especially PMVCs, dominate severe paediatric trauma and there is an urgent need for more road traffic education and stringent measures to decrease the incidence and associated morbidity and mortality.

S Afr Med J 2015;105(10):823-826. DOI:10.7196/SAMJnew.8090
\end{abstract}

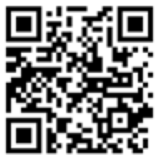

Paediatric trauma is a major cause of potentially preventable disability and mortality in South Africa (SA). ${ }^{[1]}$ In developing countries, infection and infestation account for the majority of deaths in the first 5 years of life, ${ }^{[2]}$ and much effort has been put into reducing these causes. Death from trauma extends for another decade, but despite this childhood injury continues to receive scant attention $^{[3]}$ and prevention remains rudimentary. The extent of paediatric trauma in Africa as a whole is unknown and an appeal has been made to document the burden of this problem. ${ }^{[4]}$ The limited information available suggests that motor vehicle collisions (MVCs), drowning and burns are the three commonest mechanisms causing severe injury. ${ }^{[3]}$ Although falls account for the majority of childhood injuries, ${ }^{[5]}$ MVCs are the major cause of severe morbidity and mortality. The majority involve pedestrians (PMVCs), and traumatic brain injury accounts for up to $80 \%$ of childhood trauma deaths. ${ }^{[6-9]}$

In addition to the burden of motor vehicle-related injuries, studies from Nigeria and SA have shown that gunshot wounds (GSWs) in infants and children are a tragic emerging mechanism of injury. ${ }^{[8,10,11]}$
Although the number of hospital admissions following GSWs in Cape Town decreased between 2000 and 2007, the vast majority of deaths occurred before treatment could be instituted and a steady increase in admissions was seen in the subsequent 3 years. ${ }^{[1]}$

Africa has the dubious label of being the most dangerous place in the world for a child, ${ }^{[12]}$ and prevention and political will to back up the necessary policies are the most cost-effective methods of reducing trauma-related deaths. ${ }^{[4]}$ To that end, information documenting causation, morbidity and mortality are essential for planning, implementation and evaluation of preventive measures. We therefore undertook an analysis of a prospective database of paediatric admissions to a level 1 (tertiary) trauma intensive care unit (TICU) to determine the commonest causes of injury, severity of injury and outcome.

\section{Patients and methods}

The study was approved by the University of KwaZulu-Natal Bioethics Committee (BREC 286/14) and conducted in the level 1 TICU at Inkosi Albert Luthuli Central Hospital, an academic 
tertiary hospital in Durban, SA. The TICU is an integral part of the trauma unit, which also houses resuscitation rooms equipped to the standard of the intensive care unit (ICU) and two dedicated trauma theatres. Subspecialists in critical care and trauma surgery, whose training includes the management of paediatric trauma, staff the trauma unit and TICU. There is no distinct referral pattern, and the unit accepts patients directly from the scene and from any health facility throughout KwaZulu-Natal Province (KZN). Burn injuries and drownings were excluded, as the former are managed in a separate burns unit and the latter in the medical ICU. All patients $<16$ years of age admitted to the TICU during the 5-year period January 2008 - December 2012 were identified from the unit database, which is collated by senior trauma staff on a daily basis and is independent of the hospital's electronic records system. Information extracted included referral source, age, gender and mechanism of injury (defined as MVC (pedestrian or passenger), nonvehicular blunt trauma in the form of falls and assault, GSWs, stab wounds, and other mechanisms). The injury severity score (ISS), ${ }^{[13]}$ anatomical distribution of injuries and mortality during the hospital stay were computed. Quintile age divisions into 0 - 5 , $6-10$ and $11-15$ years were analysed.

Categorical data were analysed using the $\chi^{2}$ or Fisher's exact test and continuous data by either Student's $t$-test or analysis of variance if there were more than two groups for comparison. A $p$-value of $<0.05$ was considered significant. Privacy and confidentiality was maintained and no patient was identified by name.

\section{Results}

A total of 1138 patients were admitted to the unit during the study period, of whom $181(15.9 \%)$ were $<16$ years of age. The age and gender distribution, ISS and mechanism of injury are shown in Table 1 according to quintiles of age. There were 84 females (46.4\%) and 97 males (53.6\%), with no significant difference in gender distribution. The majority of admissions were a result of blunt trauma (89.5\%), with MVCs, a combination of pedestrians and passengers, accounting for $79 \%$ of all injuries.

PMVC dominance was maintained across all quintiles of age and for every year analysed (Fig. 1). Half of the pedestrian injuries arose in the middle quintile of $6-10$ years of age. Penetrating trauma accounted for $10.5 \%$ of admissions, most commonly following GSWs. The majority of admissions (54.1\%) were in the profound ISS category, and 149 patients $(82.3 \%)$

Table 1. Age, gender, ISS and mechanism of injury in 181 paediatric admissions according to age quintiles

\begin{tabular}{lllll}
\hline & $\mathbf{0 ~ - ~ 5 ~ y e a r s ~}$ & $\mathbf{6}$ - 10 years & $\mathbf{1 1}$ - 15 years & Total \\
\hline Patients & & & & \\
$n(\%)$ & $65(35.9)$ & $80(44.2)$ & $36(19.9)$ & $181(100.0)$ \\
Age (years), mean & 4 & 8 & 13 & \\
Male, $n$ (\%) & $42(43.3)$ & $37(38.1)$ & $18(18.6)$ & $97(53.6)$ \\
Female, $n(\%)$ & $23(27.3)$ & $43(51.1)$ & $18(21.4)$ & $84(46.4)$ \\
ISS, $n$ (\%) & & & & \\
Mild $<9$ & $7(53)$ & $5(38.4)$ & $1(7.6)$ & $13(7.2)$ \\
Moderate 9 - 15 & $11(57.9)$ & $6(31.6)$ & $2(10.5)$ & $19(10.5)$ \\
Severe 16 - 25 & $15(29.4)$ & $26(50.9)$ & $10(19.6)$ & $51(28.2)$ \\
Profound >25 & $32(32.6)$ & $43(43.9)$ & $23(23.5)$ & $98(54.1)$ \\
Mechanism of injury, $n(\%)$ & & & & \\
Pedestrian MVC & $34(32.4)$ & $54(51.4)$ & $17(16.2)$ & $105(58.0)$ \\
Passenger MVC & $9(23.7)$ & $15(39.5)$ & $14(36.8)$ & $38(21.0)$ \\
Falls & $1(50.0)$ & $1(50.0)$ & - & $2(1.1)$ \\
Blunt & $6(37.5)$ & $8(50.0)$ & $2(12.5)$ & $16(8.8)$ \\
GSWs & $8(66.7)$ & $1(8.3)$ & $3(25.0)$ & $12(6.6)$ \\
Stab wounds & $5(83.3)$ & $1(16.7)$ & - & $6(3.3)$ \\
Goring & $1(100.0)$ & - & - & $1(0.5)$ \\
Cyclist & $1(100.0)$ & - & - & $1(0.5)$ \\
& & & &
\end{tabular}

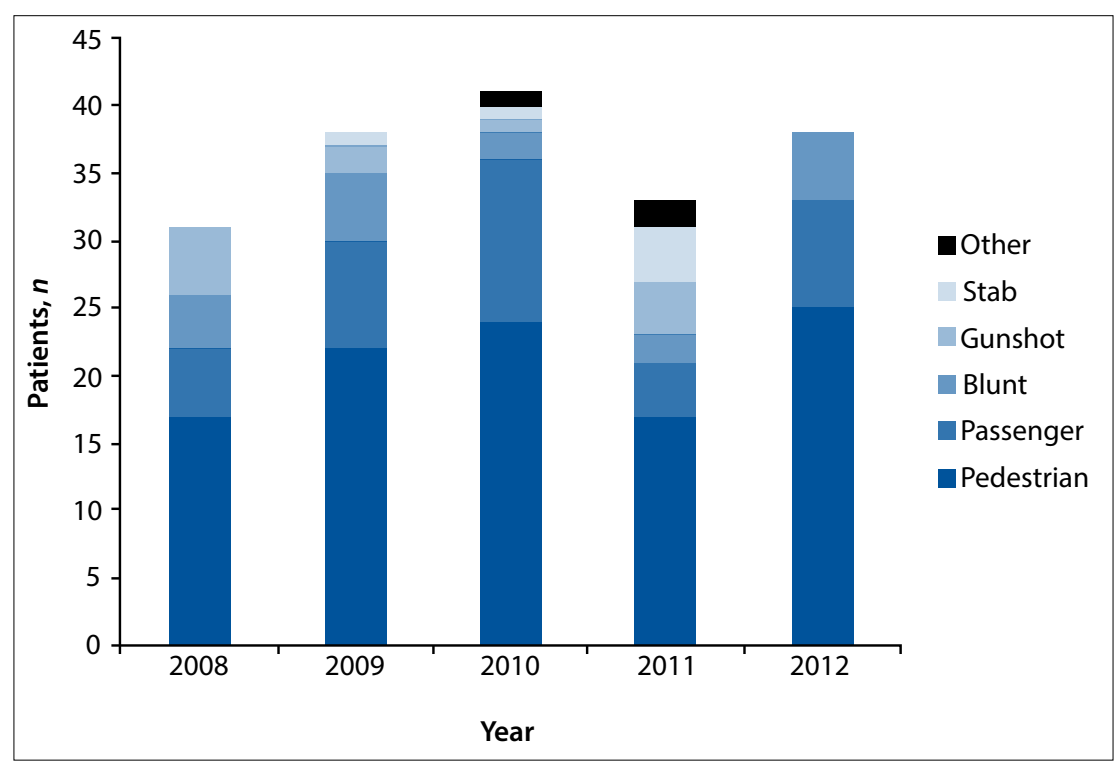

Fig. 1. Mechanisms of injury v. number of patients per year of admission (falls incorporated into blunt mechanism of injury).

had an ISS of $>16$. An average of 2.3 anatomical body regions were injured per child, with a total of 419 injuries. The anatomical distribution according to the six ISS body regions is shown in Fig. 2. Admission sources were regional hospital 56 cases $(31.0 \%)$, primary healthcare facility 47 (26.0\%), tertiary facility $40(22.0 \%)$, and from the scene $38(21.0 \%)$.

Mortality rates relative to mechanism, severity of injury and admission source are shown in Table 2. Ninety-two percent of deaths were in the profound injury severity category, which had a $24.5 \%$ mortality rate $(p<0.001)$. One child in the mild injury group died having developed acute kidney injury following blunt assault with widespread soft-tissue trauma, for which the ISS can only score one point. The remaining death was of a 7-year-old with moderate traumatic brain injury and a fractured femur, but who was HIV-positive 


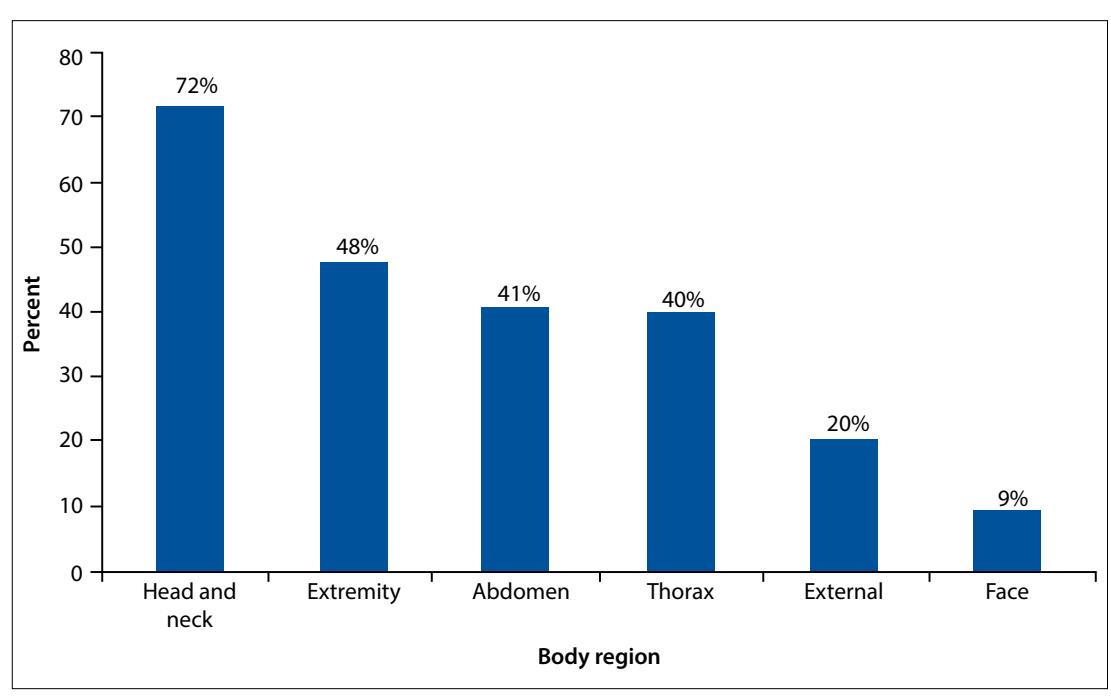

Fig. 2. Frequency (\%) of body regions injured according to ISS categories (total percentage exceeds $100 \%$ as some children sustained multiple system injuries).

Table 2. Mortality rates according to ISS, admission source and mechanism of injury

\begin{tabular}{|c|c|c|c|}
\hline & Survived, $n$ & Died, $n(\%)$ & Total, $n(\%$ \\
\hline Total & 155 & $26(14.4)$ & $181(100.0)$ \\
\hline \multicolumn{4}{|l|}{ ISS } \\
\hline Mild $<9$ & 12 & $1(7.6)$ & $13(7.2)$ \\
\hline Moderate $9-15$ & 18 & $1(5.3)$ & $19(10.5)$ \\
\hline Severe 16 - 25 & 51 & - & $51(28.2)$ \\
\hline Profound $>25$ & 74 & $24(24.5)$ & $98(54.1)$ \\
\hline \multicolumn{4}{|l|}{ Admission source } \\
\hline Scene & 34 & $4(10.5)$ & $38(21.0)$ \\
\hline Primary healthcare facility & 40 & $7(14.9)$ & $47(26.0)$ \\
\hline Regional hospital & 48 & $8(14.3)$ & $56(31.0)$ \\
\hline Tertiary hospital & 33 & $7(17.5)$ & $40(22.0)$ \\
\hline \multicolumn{4}{|l|}{ Mechanism of injury } \\
\hline PMVC & 89 & $16(15.2)$ & $105(58.0)$ \\
\hline Passenger MVC & 31 & $7(18.4)$ & $38(21.0)$ \\
\hline Falls & 2 & - & $2(1.1)$ \\
\hline Blunt & 14 & $2(12.5)$ & $16(8.8)$ \\
\hline GSW & 11 & $1(9.1)$ & $12(6.6)$ \\
\hline Stab & 6 & - & $6(3.3)$ \\
\hline Goring & 1 & - & $1(0.5)$ \\
\hline Cyclist & 1 & - & $1(0.5)$ \\
\hline
\end{tabular}

on highly active antiretroviral therapy and severely malnourished on admission.

There was no significant association of outcome with source of admission, although the mortality rate for direct admissions from the scene was on average $30 \%$ lower than that for interhospital transfers. MVCs accounted for $88.4 \%$ of deaths. Mortality rates did not differ significantly according to mechanism

\section{Discussion}

On 19 and 20 November 2009, a Global Ministerial Conference on road safety was held in Moscow, which culminated in a declaration inviting the United Nations General Assembly to declare a decade of action for road safety. The General Assembly recognised (Resolution 64/255) that the number of road traffic deaths is unacceptably high, with an estimated 1.24 million lives lost in 2010, a trend which if ignored would result in 1.9 million deaths every year to 2020. Furthermore, it was noted that only $7 \%$ of the world's population is covered by adequate laws that address behavioural risk factors including the non-use of helmets, safety belts and child restraints, driving under the influence of alcohol and drugs, inappropriate and excessive speed, and inappropriate use of cell phones while driving. Concern was also expressed that worldwide, half of all road traffic deaths involve pedestrians, motorcyclists and cyclists, and that in some developing countries there is inadequate infrastructure and a lack of policies to protect vulnerable road users. On 11 May 2011 the United Nations launched its programme 'Decade of Action for Road Safety $2011-2020$ '.

Almost half that decade has passed, and our results reflect that motor vehicle-related collisions in SA continue unabated to destroy the lives of children and their families. SA ranks among the top ten countries with the highest road traffic fatality rate per 100000 of the population, and is the second highest in Africa. ${ }^{[14]}$ One of the Millennium Development Goals identified in 2006 was a 50\% reduction in road traffic fatalities by 2015 , using 2007 as the benchmark year. Unfortunately there has been little if any improvement. Between March 2010 and March 2011 there was actually an increase in fatalities of $15 \%{ }^{[15]}$ On average, there were 1150 motor vehicle-related fatalities per month, equivalent to almost 38 per day. Paediatric pedestrian fatalities accounted for almost $25 \%$ of all pedestrian-related deaths, exceeded only by male pedestrian deaths in the 25 - 45-year age group. A similar distribution is found among passenger fatalities, with the most vulnerable paediatric age group being the second quintile of life. Unlike most of the other provinces in SA, where passengers accounted for the majority of deaths, in KZN the highest number of deaths occurred in pedestrians. Overall KZN was the worst-performing province, with a continuous increase in the quarterly number of road fatalities exceeding the set quarterly targets for the province.

Although we found no statistically significant differences in mortality in relation to referral source, the proportion of deaths among patients 
admitted directly from the scene was on average 30\% lower than among those referred from other facilities. Time to definitive care is an important determinant of outcome. The difference between time to admission to the trauma unit from the scene compared with interhospital transfer is 6 hours, ${ }^{[16]}$ owing to a lack of adequately skilled prehospital personnel. Trauma contributes to $60 \%$ of the prehospital workload in KZN. Regardless of injury severity, the majority of patients are transported to district hospitals, which have limited imaging and surgical facilities. ${ }^{[17]}$ If outcome is to be improved, delays in transfer to an appropriate level of care must be minimised, multiple transfers between health facilities discouraged, and standard referral patterns abandoned. ${ }^{[17]}$

Importantly, our mortality statistics do not reflect the extent of the trauma problem, as our results exclude deaths at the scene and address only critically injured children admitted to a level 1 TICU. For every severely injured child there are many more who have suffered less devastating injuries and are admitted to regional or district hospitals. A 10-year analysis at Red Cross War Memorial Children's Hospital in Cape Town documented almost 70000 injured children, of whom $40 \%$ had sustained moderate or severe trauma ${ }^{[5]}$ Furthermore, many of those who survive are permanently disabled as a result of severe traumatic brain injury, ${ }^{[3,4]}$ and in the public sector have little access to adequate rehabilitation facilities. The psychological, physical and economic burdens that are imposed on the individual, the family and society are incalculable.

In 2004 the National Department of Transport released a report estimating the costs of road traffic casualties. ${ }^{[18]}$ Based on the value of lost output or productivity, by making use of average life expectancy, employment rate and income of the population, the average unit human casualty cost was ZAR500 000 per fatality, ZAR200 000 per serious injury and ZAR114 000 per slight injury. Given the annual fatality rate of 14000 and a conservative estimate of three serious injuries per fatality, the annual costs are exorbitant.

In keeping with the United Nations concerns and the most recent South African National Road Agency report, ${ }^{[19]}$ our results confirm that PMVCs dominate severe childhood injuries, being almost three times as common as severe injuries of paediatric passengers. Increasing urbanisation, coupled with a lack of road safety awareness, undoubtedly contributes to the incidence, especially when small children are accompanied only by their older siblings on the way to school, a not uncommon sight on our roads. Although less common than pedestrian collisions, childhood passengerrelated trauma was associated with a higher mortality rate. On impact, unrestrained children are propelled within or ejected from the vehicle, resulting in multiple body compartment injuries. A recent amendment to the National Transport Act enforceable in April 2015 stipulates that all infants under 3 years of age must be restrained in suitable car seats and all children must wear conventional seat belts. Unfortunately this does not apply to public transport, and until the law changes children in minibus taxis or buses remain at high risk for propulsion within, or ejection from, a vehicle. Of equal concern is the transportation of unrestrained passengers in the cargo area of light delivery vehicles. In a report by Howlett et al., ${ }^{[20]}$ one-third of these were children and virtually all were ejected upon impact. Injuries to the head, spine and extremities predominated, $21 \%$ of patients died and one in ten survivors was permanently disabled, a finding commensurate with our own data. Compared with previous publications in $\mathrm{SA}_{,}^{[3,4]}$ little has changed with respect to mechanism of injury and outcome; of pedestrians or passengers with severe traumatic brain injury, more than half die.

Although motor vehicle-related paediatric trauma is quite correctly an international cause for concern, GSWs to children are equally if not more distressing, given that the majority of patients in our database were in the first 5 years of life. The youngest are injured while being carried by their mothers, typically when caught in crossfire. Tragically, similar findings have been reported from other SA studies over the past two decades. ${ }^{[10,11]}$ In KZN, Mars and Hadley ${ }^{[10]}$ reported the peak incidence of GSWs in children to occur in the first quintile of life, multisystem injuries were the commonest presentation, and of those who survived, one in ten was left severely disabled. Of major concern was their finding that 94 patients with GSWs were admitted to hospital, but three times as many died before admission and were taken straight to mortuaries, showing the heavy burden of gunshot injuries to children. In the Western Cape Province at Red Cross War Memorial Children's Hospital, Campbell et al. ${ }^{[1]}$ found the same incidence as Mars and Hadley but with a ten-fold increase in prehospital compared with in-hospital deaths. Although the Firearms Control Act of 2004 appeared to have an impact, the effect appears to be waning with a steady increase in incidence in the latter part of their study.

Internationally, road traffic injuries are the leading cause of childhood death and disability, and significant increases are predicted over the next 15 years in low- and middle-income countries. ${ }^{[21]}$ The continent of Africa especially faces major challenges. ${ }^{[4]}$ In SA the Arrive Alive campaign has identified a number of factors contributing to the unacceptable incidence of motor vehicle-related injuries, among which are the public attitude towards road safety, lack of effective policing, poor driving skills and road conditions, and rapid urbanisation. Compounding these problems are the social conditions of many children, of whom only $30 \%$ live with both parents, a significant risk factor for childhood injury whether deliberate or accidental. ${ }^{[22]}$ There is a drastic need for improved safety measures, road traffic education and stringent legislation. The single most important factor, however, is the political will to enforce such policies. ${ }^{[4]} \mathrm{Few}$ areas can be more relevant to the adage, 'Prevention is better than cure.'

\section{References}

1. Langerveld HR, van As AB. Paediatric trauma. CME 2013;31(1):5-7. http://www.cmej.org.za/index. $\mathrm{php} / \mathrm{cmej} /$ article/view/2621/2681 (accessed 4 September 2015)

2. Mortality and Causes of Death in South Africa, 2013. Findings from Death Notification. Statistics South Africa. www.statssa.gov (accessed 4 June 2015).

3. Van As AB, Miller AJW. From the pursuit for excellence to the quest for significance: Promotion of a Childsafe South Africa. S Afr Med J 2012;102(6):427-428.

. Ademuyiwa A, Usang UE, Oluwadiya KS, et al. Pediatric trauma in sub-Saharan Africa: Challenges in overcoming the scourge. J Emerg Trauma Shock 2015;5(1):55-61. [http://dx.doi.org/10.4103/0974-2700.93114] Herbert HK, van As AB, Bachani AM, et al. Patterns of pediatric injury in South Africa: An analysis of hospital data between 1996-2007. J Trauma Acute Care Surg 2012;73(1):168-174. [http://dx.doi. org//10.1097/TA.0b013E31824d67c3]

6. Semple P, Bass D, Peter J. Severe head injury in children: A preventable but forgotten epidemic. S Afr J Semple P, Bass D, Peter J. Serer $1998 ; 88(4): 440-444$.

7. Schrieff L, Thomas K, Dollman A, et al. Demographic profile of severe traumatic brain injury admissions to Red Cross War Memorial Childrens' Hospital. S Afr J Med 2013;103(9):616-620. [http:// admissions to Red Cross War Men
dx.doi.org/10.7196/SAMJ.7137]

8. Osifo D, Iribhogbe P, Ugiagbe E. Epidemiology and pattern of paediatric and adolescent trauma deaths in a level 1 trauma centre in Benin city, Nigeria. Injury 2012;43(11):1861-1864. [http://dx.doi. org/10.1016/j.injury.2011.07.016]

9. Ngambi T, Bongstein E. Epidemiology of paediatric trauma admission at Queen Elizabeth Central Hospital, Blantyre. Malawi Med Journal 2005;17(1):5-6. [http://dx.doi.org/10.4314/mmj.v17il.10860]

10. Mars M, Hadley GP. Gunshot injuries in infants and children in KwaZulu-Natal: An emerging epidemic, S Afr Med J 1998;88(4):444-447.

11. Campbell NM, Colville JG, van der Heyde Y, et al. Firearm injuries to children in Cape Town, South Africa: Impact of the 2004 Firearms Control Act. S Afr J Surg 2013;51(3):92-96. [http://dx.doi.org/10.7196/SAIS.1220]

2. Hyder AA, Peden M, Krug E. Child health must include injury prevention. Lancet 2009:373(9658):102103 [http://dx.doi.org/10.1016/S0140-6736(08)61736-5]

3. Baker SP, O'Neill B, Haddon W, Long WB. The Injury Severity Score: A method for describing patients Baker SP, O'Neill B, Haddon W, Long WB. The Injury Severity Score: A method for descith multiple injuries and evaluating emergency care. J Trauma 1974;14(3):187-196.
with

14. World Health Organization. Global Status on Road Safety 2013. Supporting a Decade of Action.

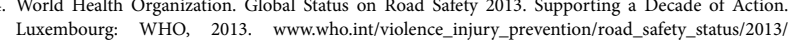
Luxembourg: WHO, 2013. www.
report/en (accessed 27 March 2015).

15. Road Traffic Management Corporation. Road Traffic Report March 2011. Faerie Glen: Department of Traffic, Republic of South Africa. http://www.rtmc.co.za/index.php/reports/traffic-reports (accessed 10 April 2015).

16. Cheddie S, Muckart DJJ, Hardcastle TC, et al. Direct admission versus inter-hospital transfer to a level I trauma unit improves survival. S Afr Med J 2011;101(3):176-178.

17. Hardcastle TC, Finlayson M, van Heerden M et al. The prehospital burden of disease due to trauma in KwaZulu-Natal: The need for Afrocentric trauma systems. World J Surg 2013;37(3):1513-1525. [http:// dx.doi.org/10.1007/s00268-012-1852-1]

18. National Department of Transport. The Estimation of Unit Costs of Road Traffic Accidents in South Africa. CR-2004/6 March 2004. Pretoria: CSIR Transportek, 2004.

19. South African National Road Agency. 2014 www.nra.co.za/content/SANRAL_Annual_Report_2104_ PRESS_14_9_15.pdf (accessed 10 April 2015).

20. Howlett JB, Aldous C, Clarke DL. Injuries sustained by passengers travelling in the cargo area of light delivery vehicles. S Afr J Surg 2014;52(2):49-52 [http://dx.doi.org /10.7196/sajs.1963)

21. World Health Organization. World Report on Child Injury Prevention www.who.int/violence_injury prevention/child/injury/world_report/en/(accessed 27 March 2015)

22. Seggie J. The $c h$ in children stands for cherish. S Afr Med J 2015;105(3):160-161 [http://dx.doi. org/10.7196/SAMJ.9452]

Accepted 24 June 2015. 